\title{
Cúvitútura
}

Vol. XV, No 1 (2021) pp. 75-107

Recibido: 5 de noviembre, 2019

Aceptado: 15 de enero, 2021

\section{ORDEN, FAMILIA Y EDUCACIÓN SEXUAL. ANÁLISIS DE LA TRAMA DE SENTIDOS EN TORNO AL MOVIMIENTO \#CONMISHIJOSNOTEMETAS EN ARGENTINA*}

Order, family and sex education. Analysis of the meanings around the \#ConMisHijosNoTeMetas movement in Argentina

\author{
Guillermo Romero $^{* *}$ \\ Universidad de Buenos Aires/CONICET \\ ORCID: 0000-0002-2538-7083
}

\section{Resumen}

El artículo se propone analizar los sentidos movilizados por la organización \#ConMisHijosNoTeMetas en Argentina a partir de la sistematización de las tres páginas oficiales que el grupo posee en la red virtual Facebook. El estudio adopta la perspectiva del análisis de contenido temático y se propone un abordaje de tipo inferencial, es decir, partiendo de los componentes estudiados y sus vinculaciones internas, así como de su puesta en relación con datos contextuales a los que dichos elementos refieren explícita y/o implícitamente, se busca reconstruir la trama de significaciones que enmarca la consigna \#ConMisHijosNoTeMetas. Este movimiento, de creciente relevancia en distintos países de Latinoamérica, cobró protagonismo en Argentina durante 2018 a partir de su enérgica oposición a un intento de reforma de la ley de Educación Sexual Integral (ESI) vigente desde el año 2006. Sin embargo, el trabajo muestra que las modificaciones propuestas operan tan solo como el

Revista Cultura \& Religión Vol. XV, 2021 Nº 1 (enero-junio) 75

Romero, G. (2021). Orden, familia y educación sexual. Análisis de la trama de sentidos en torno al movimiento \#conmishijosnotemetas en Argentina. Revista Cultura \& Religión, 15 (1), 75-107. 
fundamento inicial de estos embates, que en forma mayoritaria se dirigen a horadar algunos de los principales postulados de esta política pública, así como de todo un vasto conjunto de políticas, normas legales y discursos sociales agrupados bajo la categoría de "ideología de género".

Palabras clave: educación sexual, ideología de género, activismo católico conservador, Facebook, análisis de contenido temático.

\section{Abstract}

This article analyzes the meanings mobilized by the \#ConMisHijosNoTeMetas (don't mess with my children) organization in Argentina based on the analysis of the three official pages that the group has on Facebook. The study adopts the perspective of thematic content analysis and proposes an inferential approach, or rather, one based on the components studied and their internal connections as well as the contextualization of data to which said elements explicitly and/or implicitly refer. The goal is to create the web of meanings that the slogan \#ConMisHijosNoTeMetas encompasses. This movement, which is increasingly important in various Latin American countries, emerged in Argentina in 2018 based on energetic opposition to an attempt to reform the Comprehensive Sex Education (ESI) law that had been in place since 2006. However, the text shows that the proposed changes only operate as the initial basis for these discussions, which tend to pierce some of the main postulates of this public policy and a vast set of policies, legal standards and social discourses grouped in the category of "gender ideology."

Keywords: sex education, gender ideology, conservative Catholic activism, Facebook, thematic content analysis. 


\section{Introducción}

Este trabajo se propone analizar la trama discursiva de la organización \#ConMisHijosNoTeMetas en Argentina a través del estudio sistemático de sus cuentas oficiales de la red social Facebook. Enmarcado en la perspectiva del análisis de contenido temático (Abela, 2014), el estudio propone un abordaje de tipo inferencial: partiendo de los materiales relevados y sus vinculaciones internas, así como de su puesta en relación con datos contextuales a los que dichos elementos refieren explícita y/o implícitamente, se apuesta a reconstruir los principales sentidos sociales movilizados por el grupo.

El movimiento \#ConMisHijosNoTeMetas, de creciente relevancia en distintos países de Latinoamérica (González et al., 2018; Meneses, 2019), cobró visibilidad pública en Argentina durante 2018 a partir de su enérgica oposición a un intento de reforma de la ley 26.150 de Educación Sexual Integral (ESI) vigente desde el año 2006 (Faur, 2020; Santamarina, 2020). Dicha ley define la educación sexual integral como aquella que articula aspectos biológicos, psicológicos, sociales, afectivos y éticos, desplazándola así de su tradicional constricción a la genitalidad y al enfoque centrado en la prevención de embarazos no buscados y de enfermedades que se transmiten por vía sexual. A su vez, esta norma establece la educación sexual integral como un derecho de las y los estudiantes, y por lo tanto la erige en una obligación para la totalidad de las escuelas de gestión estatal y privada, confesionales y no confesionales. Al mismo tiempo, en su artículo $5^{\circ}$, la ley habilita a los colegios a adaptar esta política "a su ideario institucional y a las convicciones de sus miembros", planteando así una tensión con el carácter común del enfoque propuesto. Precisamente, se trata de uno de los aspectos que se propusieron modificar en los proyectos de ley presentados por distintos/as diputados/as y que en septiembre de 2018 lograron un dictamen favorable de las comisiones parlamentarias correspondientes.

En rigor, dicho artículo ha sido objeto de fuertes polémicas y debates públicos desde el momento mismo de la sanción de la ley (Esquivel, 2013). Por

Revista Cultura \& Religión Vol. XV, 2021 Nº 1 (enero-junio) 77

Romero, G. (2021). Orden, familia y educación sexual. Análisis de la trama de sentidos en torno al movimiento \#conmishijosnotemetas en Argentina. Revista Cultura \& Religión, 15 (1), 75-107 
un lado, sectores favorables a la ESI lo visualizan como una concesión hecha a la Iglesia católica que dificulta su plena implementación, especialmente en las escuelas que funcionan bajo su égida. En efecto, indagaciones previas dan cuenta que así lo han reconocido funcionarios que trabajaron en el Programa Nacional de ESI (Romero, 2017, 2018). Por su parte, actores contrarios a esta política apelan a este artículo para señalar un "contrasentido" en la formulación de la norma. En una declaración difundida luego de conocerse la aprobación de los lineamientos curriculares de la ESI, la Comisión Episcopal de Educación Católica de la Conferencia Episcopal Argentina señaló: "No se advierte cómo adaptará cada comunidad educativa los aprendizajes a su ideario institucional y a las convicciones de sus miembros, tal como prevé la misma ley si aquellos, aprobados como pautas comunes obligatorios, los contradicen, debilitan u omiten" (CEA, 2008).

De todas formas, el estudio realizado da cuenta de que el intento de reforma de esta ley resultó solo el fundamento inicial de los posicionamientos llevados adelante por el movimiento \#ConMisHijosNoTeMetas, que en forma mayoritaria se dirigieron a horadar la legitimidad tanto de la ESI en su conjunto como de todo un vasto universo de políticas públicas, normas legales y discursos sociales englobados en la categoría de "ideología de género", un concepto acuñado por el Vaticano a mediados de la década de 1990 que pretende desacreditar las demandas provenientes de los feminismos y los movimientos de la diversidad sexual, y que en los últimos años opera como una zona de confluencia de un activismo interreligioso transnacional que, paradójicamente, irrumpe en cada contexto local denunciando su presencia como una suerte de "colonialismo cultural" que amenaza sus valores y tradiciones (Faur y Viveros, 2020; Santamarina, 2020; Tabbush y Caminotti, 2020). Acorde a una estrategia característica del activismo religioso aggiornado a la vida democrática-moderna que Juan Marco Vaggione ha llamado "secularismo estratégico" (2009), en su trama argumental este grupo no suele poner de relieve su carácter religioso, sino que se presenta como un grupo de

Revista Cultura \& Religión Vol. XV, 2021 № 1 (enero-junio) 
"familias" o "padres" preocupados por la educación de sus hijos, cariz discursivo coincidente con los empleados por los movimientos "provida" y "profamilia" en escenarios previos (Felitti, 2011; Gudiño, 2014; Jones y Vaggione, 2012; Morán, 2012, 2015, 2018). ${ }^{1}$ Sus referentes, empero, pertenecen a distintos grupos cristianos (católicos y evangélicos), en una alianza estratégica ${ }^{2}$ que en Argentina resulta palmaria al menos desde el debate y posterior aprobación del matrimonio entre personas del mismo sexo en 2010 (Jones y Carbonelli, 2015; Jones y Vaggione, 2012). Esta adscripción religiosa, que en las movilizaciones realizadas por la organización resulta explícita por la abundancia de una simbología devocional, en los materiales indagados en este trabajo tiene en cambio una presencia difusa. Los argumentos esgrimidos suelen abrevar en saberes científicos (fundamentalmente médicos, biológicos y psicológicos), así como en una idea de "moral pública" y "sentido común" presentados como evidentes. De este modo, los valores tradicionales de una mentada "mayoría silenciosa" se exhiben como amenazados por una "minoría activa" movilizada por intereses espurios cuando no perversos, aunque sus contornos nunca llegan a delinearse con total claridad. Es precisamente allí, en la vaguedad característica de estos enunciados, donde se refuerza un sentido de amenaza latente y de desorden generalizado que afectaría al "bien común" que este grupo se propondría salvaguardar (Tabbush y Caminotti, 2020).

Dicho escenario habilita la expresión de sentimientos de "ofensa moral" que, de acuerdo a Viotti (2020), se encuentran en la base de los activismos conservadores y autoritarios contemporáneos. En esta clave, la denuncia de la

\footnotetext{
${ }^{1}$ Ya en la Conferencia de Beijing, realizada en 1995, el Vaticano decidió cambiar su estrategia y reemplazar a la habitual delegación de obispos por representantes laicos. Desde entonces su oposición a las políticas de ampliación de los derechos sexuales y (no) reproductivos apelan a una retórica jurídico-médica-secular y no explícitamente religiosa (Gudiño, 2016; Santamarina, 2020).

${ }^{2}$ Tras la Conferencia de El Cairo, en 1994, en la que se exhortó a los gobiernos a establecer políticas activas en materia de educación sexual, equidad de género y salud reproductiva, algunos líderes católicos y evangélicos sellaron una alianza global para frenar el avance de la agenda de género impulsada por los movimientos feministas y de la diversidad sexual, que expresaron en el documento "Evangélicos y católicos juntos: La misión cristiana en el tercer milenio" (Biroli, 2020; Faur y Viveros, 2020; Santamarina, 2020).
}

Revista Cultura \& Religión Vol. XV, 2021 Nº 1 (enero-junio) 
"ideología de género" podría ser pensada como una herramienta epistemológica que permita integrar conceptos tradicionales del activismo "provida" y "profamilia" dentro de una estrategia discursiva defensiva más amplia. De este modo, los discursos neoconservadores darían cuenta no solo de enfoques ideológicos sistemáticos, vinculados a grupos e instituciones sociales (como el aquí estudiado), sino además de la existencia de una nueva "sensibilidad cotidiana" caracterizada por el sentimiento de una ofensa moral frente a transformaciones socioculturales visualizadas como causantes de desorden, incertidumbre y temor (Viotti, 2020).

Por otra parte, en tanto las páginas de Facebook analizadas no resultan meras plataformas donde se plasman los sentidos previa y plenamente constituidos por la organización, el trabajo se enfoca específicamente en la trama de significaciones (re)creadas en estos dispositivos a partir del uso de los múltiples recursos habilitados por esta red digital virtual. De este modo, al mismo tiempo que recupera los estudios previos focalizados en el activismo "religioso/conservador" y su utilización de los medios de comunicación masiva (Bracamonte, 2015; Campos, 2013; Cáneva, 2019; Fabris, 2015; Sgró, 2019), esta indagación pretende asimismo aportar a comprender las dinámicas de transformación y reactualización de estos movimientos sociales.

\section{1. \#ConMisHijosNoTeMetas. Contexto local de emergencia}

Es imperioso entender que el aborto fue tan sólo un árbol en el medio de un bosque y que ese bosque se llama ideología de género y que esa ideología se hará obligatoria a través de la mal llamada educación sexual integral. (Agustín Laje cit. en Con mis hijos no te metas Argentina Oficial, 26 noviembre de 2018, s. p.).

La organización Con mis hijos no te metas irrumpió por primera vez en el espacio público en Perú en diciembre de 2016, en oposición a un intento infructuoso de reforma del Currículo Nacional de Educación Básica al que se acusó de incorporar en su seno la "ideología de género" (Meneses, 2019;

Revista Cultura \& Religión Vol. XV, 2021 № 1 (enero-junio) 80

Romero, G. (2021). Orden, familia y educación sexual. Análisis de la trama de sentidos en torno al movimiento \#conmishijosnotemetas en Argentina. Revista Cultura \& Religión, 15 (1), 75-107 
Santamarina, 2020). El lema "con mis hijos no te metas", que había sido formulado en un encuentro de movimientos cristianos y personalidades políticas peruanas y colombianas realizado en Lima en noviembre de 2016, no tardó en expandirse por todo el continente y fue adoptado por distintos colectivos autodenominados "provida" y "profamilia" con una historia previa de oposición a la ampliación de derechos sexuales y (no) reproductivos.

De este modo, \#ConMisHijosNoTeMetas constituye un nuevo eslabón dentro del proceso de creciente "ONGeización" del movimiento provida en Argentina y América Latina (Morán, 2015), es decir, de proliferación de organizaciones no gubernamentales (ONG) que utilizan los mecanismos propios del juego democrático (lobby parlamentario, activismo judicial, manifestaciones callejeras, estrategias comunicacionales) para movilizar posiciones alineadas con la agenda sexual de la Iglesia católica y algunas iglesias evangélicas, pero desde un activismo civil o "laico"” (Felitti, 2011; Gudiño, 2014; Morán, 2015; Vaggione, 2009).

En Argentina, \#ConMisHijosNoTeMetas se conformó en 2017, unos meses después de su emergencia en Perú. La organización cuenta con tres coordinadoras nacionales (María Ángeles Márquez, Nancy García y Naomí Vera) y un vocero (Néstor Mercado), quienes resultan las únicas autoridades oficiales del movimiento en el país. Aunque el elemento que desencadenó su vertiginosa irrupción en el espacio público fue el mencionado intento de modificar la ESI, se trató indudablemente de un emergente del contexto de politización social experimentado dicho año a partir del inédito debate en el Congreso Nacional en torno a un proyecto de ley que proponía la despenalización y legalización de la interrupción voluntaria del embarazo dentro de las primeras 14 semanas de gestación. Iniciativa impulsada por la

\footnotetext{
${ }^{3}$ El término "laico" es utilizado por la Iglesia católica en referencia a sus miembros "no consagrados", es decir, que no ejercen sacerdocio ni "tomaron los hábitos". En efecto, la Conferencia Episcopal Argentina cuenta con un Departamento de Laicos (Deplai) que tiene el objeto de coordinar las acciones del vasto conjunto de organizaciones civiles vinculadas a la Iglesia católica que operan en el país.
}

Revista Cultura \& Religión Vol. XV, 2021 № 1 (enero-junio) 
Campaña Nacional por el Derecho al Aborto Legal, Seguro y Gratuito, que contó con la firma de 71 diputados/as de diferentes fuerzas políticas.

Si bien no era la primera vez que se impulsaba un proyecto de estas características, la particularidad del caso estuvo dada por el hecho de que desde distintos sectores del entonces partido gobernante dejaron trascender que en esta ocasión permitirían su votación en el recinto. Esto generó una enorme expectativa en el movimiento feminista, al punto que desde el comienzo del año hubo una gran cantidad de acciones militantes en apoyo a la iniciativa. Durante los meses de abril y mayo se desarrolló dos veces por semana una serie de "audiencias informativas" en las que alrededor de 700 especialistas en diversas áreas fueron desplegando sus argumentos a favor o en contra del proyecto. Estas jornadas fueron acompañadas por grandes manifestaciones, principalmente del movimiento de mujeres, identificado con pañuelos de color verde.

Con una menor masividad y visibilidad pública, quienes se oponían al proyecto comenzaron a movilizarse e identificarse con pañuelos celestes. De a poco, a medida que se acercaba el momento del debate parlamentario y la votación en el Congreso, este sector fue cobrando mayor intensidad. Frente a la denominada "marea verde", fue tomando brío la llamada "ola celeste".

Finalmente el 13 de junio el proyecto fue tratado por la Cámara de Diputados. El operativo de seguridad decidió vallar la plaza ubicada frente al Congreso de la Nación, asignando la misma extensión a los/as partidarios/as de cada una de las posiciones, lo que permitió visualizar la enorme disparidad entre la masividad de quienes estaban a favor de la iniciativa y la menor cantidad de personas movilizadas en contra. Luego de más de 22 horas de debate parlamentario, el proyecto obtuvo la media sanción ${ }^{4}$ con un total de 129 votos contra 125.

\footnotetext{
${ }^{4}$ En Argentina, el Congreso de la Nación está compuesto por dos cuerpos: la Cámara de Diputados y la Cámara de Senadores. Para convertirse en ley, el proyecto que proponía la despenalización y legalización de la interrupción voluntaria del embarazo debía obtener una mayoría simple en ambos recintos legislativos.
}

Revista Cultura \& Religión Vol. XV, 2021 № 1 (enero-junio) 
A partir de entonces, la Iglesia católica, en conjunto con algunas iglesias evangélicas, comenzó una activa campaña para movilizar a quienes se oponían al proyecto. Cuando el 8 de agosto la Cámara de Senadores votó la iniciativa aprobada dos meses atrás por los/as diputados/as, la movilización de la "ola celeste" había ganado en volumen e intensidad. Sin llegar a equipararse a la "marea verde", había logrado de todos modos expresar la existencia de amplios sectores de la sociedad contrarios a la iniciativa. Tal como se preveía, el proyecto fue rechazado por 38 votos contra $31 .^{5}$

Si bien para el movimiento de mujeres se trató de una conquista relativa por haber logrado darle audibilidad a un debate largamente postergado, para quienes comandaron la organización de la negativa se trató de un triunfo rotundo. No solo por haber frenado de momento la iniciativa, sino también por el hecho de haber alcanzado una importante capacidad de movilización, algo que sus principales impulsores, grupos católicos y evangélicos, volverían a lograr unas semanas después para oponerse a los intentos de reforma de la ley de ESI, esta vez bajo el lema \#ConMisHijosNoTeMetas.

\section{Aspectos metodológicos y descripción de la unidad de análisis}

Aunque la organización ya venía realizando distintas acciones militantes desde mediados de 2017 (como charlas, talleres, campañas de comunicación), lo que dio impulso y resonancia pública al activismo de este grupo fue su enérgico rechazo al intento de modificación de la ley 26.150. En el mes de septiembre de 2018, luego de que los proyectos presentados por distintos/as diputados/as para reformar la ESI obtuvieran dictamen favorable de las comisiones legislativas de Educación y Familia (quedando de ese modo en condiciones de ser votados en el recinto), el movimiento incrementó su

\footnotetext{
${ }^{5}$ Dos años más tarde, en diciembre de 2020, un proyecto de legalización del aborto -enviado por el nuevo gobierno encabezado por Alberto Fernández (de signo contrario al anterior) obtuvo mayoría en ambas cámaras legislativas y logró consagrar el derecho a decidir la interrupción voluntaria del embarazo establecido por la ley 27.610 .
}

Revista Cultura \& Religión Vol. XV, 2021 № 1 (enero-junio) 
actividad, llegando a realizar un conjunto de marchas multitudinarias en distintas ciudades del país el día 28 de octubre.

Si bien durante esos días sus tres coordinadoras nacionales, así como su vocero oficial tuvieron cierta presencia en distintos medios de comunicación masiva, el grupo asignó especial atención dentro de sus estrategias comunicacionales a la utilización de las redes digitales virtuales propias, entre ellas las páginas de Facebook que analizo aquí. Herramientas que fueron empleadas para convocar y comunicar las acciones del movimiento, como así también para difundir materiales elaborados por terceros, pero que de alguna manera contribuyen a reforzar los argumentos del grupo y a rebatir o deslegitimar los discursos y los actores identificados como adversarios, principalmente el feminismo y el activismo de la diversidad sexual.

Uno de los criterios para centrarnos en esta plataforma (habiendo otras también empleadas por la organización ${ }^{6}$ ) estuvo vinculado a que se trata de la red social digital más utilizada en el país. De acuerdo con los datos de la Encuesta Nacional de Consumos Culturales (Sistema de Información Cultural de la Argentina, 2017), en Argentina el 64,4\% de sus habitantes posee una cuenta de Facebook. Por otro lado, a diferencia de Twitter, que pese a ser otra de las redes digitales con gran pregnancia es un espacio más adecuado para la confrontación y la polémica, Facebook se destaca como "una plataforma que celebra y hace explícitos los vínculos de afinidad y amistad, reforzando la idea de lo comunitario, bajo la forma de una comunidad virtual" (Cáneva, 2019, p.109). Así, aun cuando algunos de los materiales indagados asumen un carácter polémico, no se trata de un espacio de debate sino de formación, confirmación y consolidación del colectivo (Santamarina, 2020). De modo que, en función de los intereses de este trabajo (comprender los sentidos sociales movilizados por el grupo), se constituía en un ámbito de suma pertinencia. A su vez, debido a su formato generalista y simplificador (Ghidoli cit. en Cáneva,

${ }^{6}$ El trabajo de Sofía Santamarina (2020) explora el uso de la totalidad de las redes sociales digitales por parte del movimiento.

Revista Cultura \& Religión Vol. XV, 2021 Nº 1 (enero-junio) 
2019), Facebook posibilita la elaboración, circulación y consumo de textos escritos, imágenes fijas y móviles, aun a aquellos usuarios no familiarizados con las tecnologías digitales. Esto se debe, en parte, a la iconización del formato, que permite un manejo intuitivo de las funciones disponibles (Cáneva, 2019).

En un primer trabajo de relevamiento hallé cerca de una decena de perfiles de Facebook que asumían el nombre de la organización, entre "grupos" y "páginas", por lo que se me presentó el interrogante respecto de los criterios a tener en cuenta con el fin de conformar la unidad de análisis. Resulta interesante resaltar que las páginas expresan los posicionamientos de una entidad institucional, como puede ser una empresa o, en este caso, una organización. De este modo, aun cuando se trate de sitios administrados por una o más personas, el contenido publicado es atribuido a dicha entidad. A su vez, en la medida en que se trata de un perfil público, cualquier usuario de la red puede acceder a ese contenido e interactuar con él. Los grupos de Facebook, en cambio, operan bajo la lógica de "comunidad virtual". Su propósito es el de compartir publicaciones sobre un tema específico. Aunque existen distintas modalidades de funcionamiento (abiertos, cerrados o secretos), solo es posible comentar, publicar $\mathrm{y}$, en algunos casos, acceder a ellos una vez que se es aceptado como miembro.

En la medida en que el propósito del trabajo consiste en comprender la trama discursiva configurada por este actor social, decidí concentrarme en las tres páginas que la organización asume como propias: Con mis hijos no te metas Argentina Oficial, Con Mis Hijos No Te Metas Rca. Argentina-Oficial- y Con Mis Hijos No Te Metas República Argentina Buenos Aires "oficial". Por otro lado, interesa adelantar que el artículo no esboza un análisis pormenorizado de las representaciones de los diferentes actores que tienen presencia en las publicaciones de estas páginas, sino de los sentidos sociales activados por el movimiento concebido como un actor colectivo. Por ello mismo, otra decisión teórico-metodológica central en la conformación del corpus fue trabajar con las

Revista Cultura \& Religión Vol. XV, 2021 № 1 (enero-junio) 
publicaciones (o, en los términos del lenguaje de la propia plataforma, “entradas”) realizadas por estos perfiles públicos, asumiendo los comentarios (y demás interacciones) de otros usuarios de la plataforma como parte del contexto que enmarca al material indagado.

El período seleccionado para la muestra abarca desde el mes de septiembre de 2018, momento en el que se intensificaron las acciones del movimiento, hasta marzo de 2019, con el fin de incluir las publicaciones en torno al Paro internacional de mujeres (realizado el día 8 de marzo) y la Marcha por la vida (realizada ese año el 23 de marzo $^{7}$ ), fechas consideradas significativas para el grupo. En función de estos criterios, el corpus confeccionado comprende un total de 682 entradas.

La cantidad, la heterogeneidad y el volumen de los materiales difundidos a través de estas páginas durante este período habilitan múltiples entradas analíticas. En este caso me centré en el análisis de contenido temático, dejando de lado otros aspectos relevantes que futuros trabajos podrían retomar, como los recursos estéticos, estilísticos y genéricos utilizados.

El análisis de contenido temático constituye una técnica de interpretación de distintas textualidades que, empleada en forma sistemática y rigurosa, "nos abre las puertas al conocimiento de diversos aspectos y fenómenos de la vida social" (Abela, 2014, p. 2). Aquí me concentré especialmente en los enunciados verbales, orales o escritos, con el fin de identificar los temas abordados, las figuras e instituciones presentadas como referencias legítimas e ilegítimas y las principales estrategias discursivas y argumentales desplegadas.

En la medida en que analizo materiales que son ricos en información que no se expresa de manera literal, el estudio sigue una lógica inductiva. Es decir, a partir de los elementos sujetos a análisis y sus vinculaciones internas,

\footnotetext{
${ }^{7}$ En Argentina y en otros países, algunos sectores católicos celebran cada 25 de marzo el Día del Niño por Nacer. En la medida en que en este caso dicha fecha coincidía con un día laborable (lunes), y que el domingo 24 se realizan masivas movilizaciones y actos conmemorativos de la última dictadura cívico-militar-eclesiástica que sufrió el país entre los años 1976 y 1983, los organizadores de la marcha decidieron hacerla el sábado 23.
}

Revista Cultura \& Religión Vol. XV, 2021 Nº 1 (enero-junio) 
así como de su puesta en relación con datos contextuales a los que dichos elementos refieren explícita y/o implícitamente, apuesto a reconstruir los sentidos sociales movilizados por el grupo. Como señala Abela (2014), "tanto los datos expresos (lo que el autor dice) como los latentes (lo que dice sin pretenderlo) cobran sentido y pueden ser captados dentro de un contexto" (2014, p. 2). Acorde a la perspectiva teórica de los estudios culturales que asumo como enfoque general, en lugar de comenzar la indagación con un marco de condicionamientos preestablecido opté por partir de los propios materiales para, desde allí, reconstruir sus contextos específicos (Grossberg, 2009).

Las tres páginas seleccionadas mantuvieron una intensa actividad a lo largo de este período, con al menos tres actualizaciones semanales, incrementándose los días previos y posteriores a las principales acciones militantes realizadas por el movimiento. Con mis hijos no te metas Argentina Oficial fue creada el 15 de mayo de 2017 y contaba con 57.377 seguidores al 31 de marzo de 2019. ${ }^{8}$ Con Mis Hijos No Te Metas Rca. Argentina-Oficial-, en tanto, inició su actividad el 4 de abril de 2018 y la seguían 31.202 perfiles de Facebook. Por su parte, Con Mis Hijos No Te Metas República Argentina Buenos Aires "oficial" es la más reciente de las tres: comenzó a funcionar los días previos a la ya mencionada marcha del 25 de octubre de 2018 y tenía 3.016 seguidores.

En los tres sitios se recupera como imágenes principales de sus portadas el hashtag \#ConMisHijosNoTeMetas, escrito en letras blancas sobre un fondo dividido en partes iguales por los colores celeste y rosa que caracterizan al movimiento en todo el mundo, a la vez que la utilización de la bandera argentina les aporta un símbolo de pertenencia distintivo respecto de otros países (ver Imagen $\mathrm{N}^{\circ} 1$ e Imagen $\mathrm{N}^{\circ} 2$ ).

\footnotetext{
${ }^{8}$ En los tres casos, la última consulta fue realizada el 31 de marzo de 2019.
} 
Imagen $\mathbf{N}^{\circ} 1$ : Portada del sitio Con mis hijos no te metas Argentina Oficial

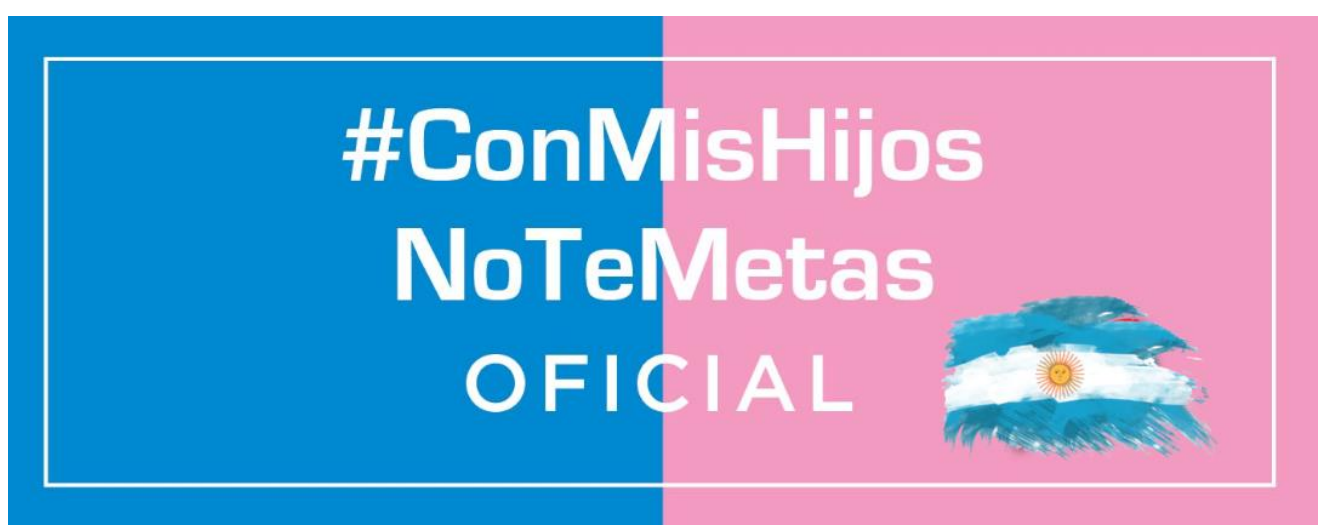

La división en dos $-\mathrm{y}$ solo dos- colores remite al modelo binario (celeste $=$ varón, rosa=mujer) que estos sectores propugnan como modelo familiar natural y, al menos en algunos enunciados, acorde a la creación divina. En la propia descripción de la página Con mis hijos no te metas Argentina Oficial se define al grupo como "profamilia (matrimonio hombre y mujer)".

La centralidad de la familia nuclear heterosexual aparece todavía con más fuerza en la imagen escogida para la portada en las otras dos páginas relevadas (ver Imagen $\mathrm{N}^{\circ} 2$ ), donde además se refuerza el carácter tutelar del mundo adulto respecto de la niñez. Allí el binarismo sexual que se proclama como propio del "orden natural" aparece acentuado por los colores asignados a los sujetos de acuerdo al sexo. Además, la imagen refuerza un sentido de resguardo de la familia, con el padre y la madre puestos en un primer plano negando la intromisión de una amenaza externa a sus hijos, incluido el "niño por nacer", a quien también se le asigna un sexo inequívoco (en este caso, dado que aparece en celeste, se trataría de un varón).

Revista Cultura \& Religión Vol. XV, 2021 № 1 (enero-junio) 
Imagen $\mathbf{N}^{\circ}$ 2: Portada de las páginas Con Mis Hijos No Te Metas Rca. Argentina-Oficial- y Con Mis Hijos No Te Metas República Argentina Buenos Aires "oficial"

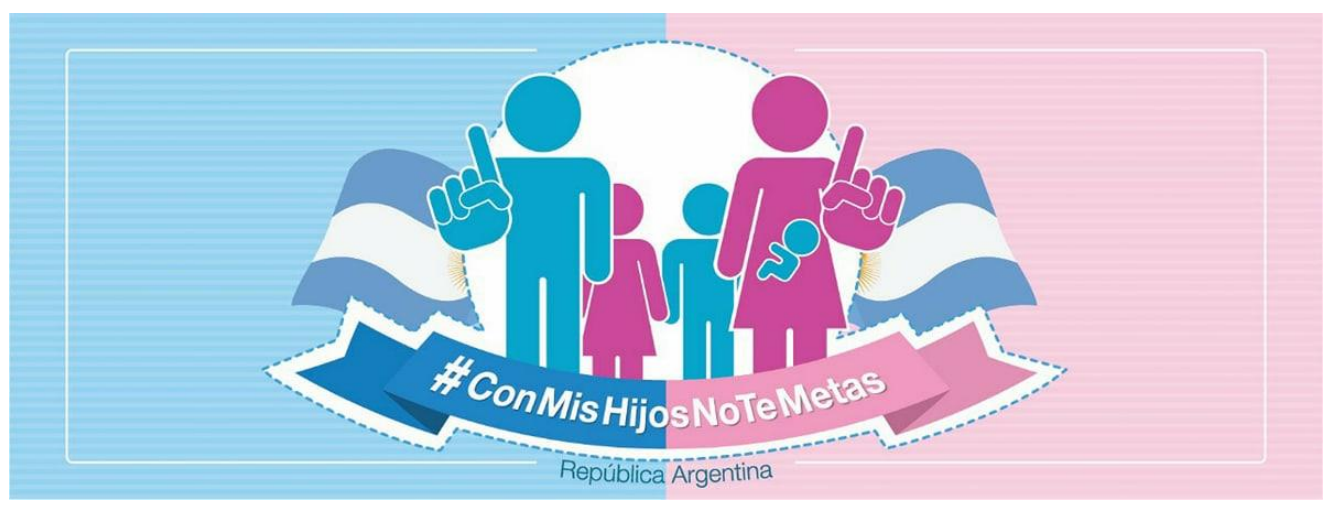

Al igual que en los demás países, la utilización del hashtag para nombrar a la organización expresa la centralidad conferida a las redes sociales virtuales dentro de la campaña contra la implementación de una política de educación sexual con "ideología de género" en las escuelas. A su vez, la presencia de la bandera argentina en la imagen busca darle un anclaje local al movimiento, aspecto que como veremos más adelante constituye un elemento central de las estrategias discursivas del grupo.

En los tres casos se trata de portales administrados por pocas personas (no más de cinco), lo que muestra cierta concentración organizativa. En la medida en que luego de una sistematización del material relevado no hallé diferencias relevantes para los propósitos del trabajo entre cada una de estas páginas, opté por establecer un análisis transversal de las mismas. En este marco, la pregunta rectora del artículo es: ¿qué trama significativa construyen estos sitios en torno a las políticas de educación sexual, en particular a la ESI, y, en general, a lo que denominan "ideología de género"? 


\section{Con mis hijos no. En defensa de "nuestros" valores}

Están utilizando al Estado para hacer obligatoria su ideología. (A. Laje cit. en Con mis hijos no te metas Argentina Oficial, 28 noviembre de 2018, s. p.).

"Nuestros hijos no son del Estado", "A mis hijos los educo yo", "Con mis hijos no". Las frases, inscriptas en pancartas enarboladas en una de las movilizaciones convocadas en Buenos Aires bajo el lema \#ConMisHijosNoTeMetas, sintetizan una de las tensiones fundamentales sobre las que se posa el discurso de este movimiento ciudadano: el derecho de o sobre los/as hijos/as.

En Argentina hace más de una década que la legislación que regula los derechos de la niñez, en general, y de los y las estudiantes, en particular, coincide en conceptualizar a niñas, niños y adolescentes como sujetos de derecho. Así lo establecen, entre otras, la ley de Protección Integral de los Derechos de la Niñez y la Adolescencia ( $N^{o}$ 26.061, de 2005), la ley de Educación Nacional ( $\mathrm{N}^{\mathrm{0}}$ 26.206, de 2006), así como la mencionada ley de Educación Sexual Integral ( $N^{0}$ 26.150, de 2006). Sin embargo, ese acervo normativo lejos está de ser el fruto de un extendido consenso social, particularmente en lo que respecta a temáticas vinculadas al género y la sexualidad en el ámbito educativo. En un texto polémico editado por la Iglesia católica argentina a pocas semanas de haberse sancionado la ESI, se señala que "son los padres quienes tienen el derecho y el deber de la educación de los hijos" (CEA, 2007, p. 9), pudiendo la escuela cumplir apenas un rol subsidiario respecto de dicha enseñanza. En el mismo trabajo, titulado Educación para el amor, se cita parte del documento papal Familiaris Consortio, el cual establece: "la Iglesia reafirma la ley de subsidiariedad que la escuela tiene que observar cuando coopera en la educación sexual, situándose en el espíritu mismo que anima a los padres" (cit. en CEA, 2007, p. 10).

Este antiguo debate que trama las discusiones históricas en torno a la laicidad en Argentina (Esquivel, 2013; Torres, 2014) se reactualizó una vez más

Revista Cultura \& Religión Vol. XV, 2021 Nº 1 (enero-junio) 90

Romero, G. (2021). Orden, familia y educación sexual. Análisis de la trama de sentidos en torno al movimiento \#conmishijosnotemetas en Argentina. Revista Cultura \& Religión, 15 (1), 75-107 
ante el intento de reforma de la ESI. El vocero oficial de la organización en el país, Néstor Mercado, señala que al pretender modificar el mencionado artículo $5^{\circ}$, "se quiere quitar la posibilidad de que los papás sean parte de la comunidad educativa. Es decir, quieren a los papás fuera. Quitándonos la patria potestad, quitándonos de la comunidad educativa" (Con Mis Hijos No Te Metas Rca. Argentina-Oficial-, 13 noviembre de 2018, s. p.). Y en otro pasaje del mismo discurso plantea: "El tema de impedir que las escuelas confesionales sigan un ideario ético no es un ataque a la escuela, es un ataque a la familia, es un ataque a los padres" (Con Mis Hijos No Te Metas Rca. Argentina-Oficial-, 13 noviembre de 2018).

Como puede verse, las referencias a los idearios religiosos cristianos son más bien implícitas. El énfasis está puesto principalmente en la "defensa de la familia", en el "derecho de los padres a educar a sus hijos según sus valores". En este sentido, Nancy García, una de las coordinadoras a nivel nacional del movimiento, señalaba en un acto realizado frente al Congreso de la Nación, en referencia a los/as niños/as: "Si bien no son nuestra propiedad, son nuestra primera responsabilidad" (Con Mis Hijos No Te Metas Argentina Oficial, 8 de noviembre de 2018a).

Por otra parte, la trama argumental de estos posicionamientos suele recurrir a una permanente oposición entre el saber científico y la ideología (de género). De este modo, el movimiento plantea que no se opone a la educación sexual, sino a una visión sesgada e interesada (no científica) de la misma. “Educación sexual para prevenir, sí; ideología de género para adoctrinar, no", es una de las consignas que condensa esta postura.

Desde este punto de vista, los únicos saberes válidos para referirse a estos asuntos son los biomédicos, especialmente con fines "preventivos". Como señala un spot elaborado para oponerse a la reforma: "la biología, la ciencia y la gente dicen: \#ConMisHijosNoTeMetas" (Con mis hijos no te metas Argentina Oficial, 8 noviembre de 2018b). Posicionamiento que puede advertirse, asimismo, en distintas frases exhibidas en los carteles durante las 
movilizaciones convocadas por el movimiento (y luego replicadas en sus páginas de Facebook): "La escuela debe enseñar verdades biológicas, no ideológicas", “Ideología es pervertir”. Así, la biología (concebida por fuera de condicionantes socioculturales) es considerada "educación", mientras que la mentada ideología de género resultaría "adoctrinamiento".

La noción de adoctrinamiento, empleada en forma recurrente, conlleva implícita la idea de ciertos fines espurios que operarían de fondo, identificados fundamentalmente como un ataque a "nuestros valores y costumbres tradicionales". De ese modo, la ESI se presenta como un eslabón más de una poderosa amenaza "externa", representación que aparece plasmada en el discurso del pastor evangélico Alberto Savazzini en un acto realizado el 28 de octubre de 2018 en Buenos Aires:

Hace tiempo un grupo de personas perversas desarrollaron un programa que intenta desintegrar nuestras familias. En todo el mundo se está tratando de implementar este sistema que lo único que intenta es retirarle a los padres el derecho legítimo que tenemos a educar a nuestros hijos de acuerdo a nuestros valores, de acuerdo a nuestras convicciones y de acuerdo a nuestras realidades. Estas personas están plasmadas en el grupo poderoso que rigen o que pretenden regir el destino de nuestra nación y de otras naciones. El stablishment poderoso económico del mundo se está metiendo con el derecho que nosotros tenemos a educar a nuestros hijos. (Con mis hijos no te metas Argentina Oficial, 8 noviembre de 2018c, s. p.).

En este marco de significaciones, el lugar estratégico que tendría la educación sexual estaría dado por el hecho de que pretende destruir a la familia (así, en singular), aprovechándose de su pieza más endeble: la inocencia y mayor vulnerabilidad de "los niños". De allí la importancia de que estos sean tutelados por los padres y no por el Estado, ente que se presenta como partícipe necesario (por acción u omisión) de una confabulación internacional para propagar la "ideología de género". Idea que constituye uno de los principales núcleos argumentales del movimiento, si bien los distintos materiales relevados

Revista Cultura \& Religión Vol. XV, 2021 N 1 (enero-junio) 92 
difieren en los actores que nombran como principales promotores de esa estrategia. El listado puede incluir a "los medios" [de comunicación masiva], "el Estado", "los gobiernos", "los partidos políticos tradicionales" o "hegemónicos", el "lobby pedófilo", el "lobby LGBT", "las multinacionales", "el stablishment financiero", "el FMI" y "la ONU”, entre otros. Ejemplo de esta deriva es el siguiente fragmento de un video de Agustín Laje, ${ }^{9}$ uno de los actores con mayor frecuencia de aparición en las publicaciones de estas páginas:

Nosotros no vamos a tener la plata de George Soros, de Rockefeller, el apoyo de la ONU, la plata de los abortos de Planned Parenthood. No vamos a tener los partidos políticos organizados hegemónicos. Lo único que tenemos es gente de a pie con sus familias que le dice al Estado, por ejemplo, con mis hijos no te metas, no te metas con mi libertad (Laje cit. en Con Mis Hijos No Te Metas Rca. Argentina-Oficial-, 31 diciembre de 2018, s. p.).

Este modo de presentar el conflicto presume la puesta en acto de una batalla excesivamente desigual y por lo tanto heroica por parte del movimiento, frente a un enemigo cuya figuración no termina de perfilarse con nitidez en las distintas enunciaciones, pero que indudablemente supondría una concertación fenomenal de intereses ilegítimos, al punto que no resulta extraña la recurrente evocación en los posteos del relato bíblico de David y Goliat, ${ }^{10}$ como se observa en el siguiente fragmento: "Cómo se nota que tienen mucha guita [dinero] detrás, es una batalla muy injusta, David contra Goliat... pero ya sabemos cómo terminó esa historia. ¡Sigamos enfrentando a esta mafia abortera y adoctrinadora de género! ¡A no bajar los brazos!” (Con Mis Hijos No Te Metas República Argentina Buenos Aires "oficial", 11 de diciembre de 2018).

9 Video disponible en

https://www.facebook.com/permalink.php?story_fbid=295615604492682\&id=1716061702269 60

${ }^{10}$ En referencia al relato bíblico en el que el joven e inexperto en el arte de la guerra, David, vence en la batalla al fuerte, experimentado y bien pertrechado Goliat.

Revista Cultura \& Religión Vol. XV, 2021 Nº 1 (enero-junio) 
Además de ponerse de relieve la disparidad de la disputa, este antagonismo se exhibe a su vez como una distinción moral taxativa, ya que a la "gente de a pie con sus familias" no la moviliza "la plata de George Soros", sino una causa repleta de nobleza: la defensa de sus "hijos" y de su "libertad".

De acuerdo con esta visión, el Estado, que otrora habría funcionado para servir a los intereses de "la familia" (presentada recurrentemente como "célula básica de la sociedad"), ahora se encontraría cooptado por actores, discursos e intereses vinculados a la "ideología de género", por lo que se vuelve el principal actor a quien dirigir las críticas y las demandas. Al mostrarse en forma reiterada que, por ejemplo, algunas instituciones educativas asumen posturas contrarias al ideario pregonado por el movimiento, se las erige como intolerantes a la heterogeneidad de opiniones y al disenso, invirtiendo así una acusación habitual que suele dirigirse a los activistas religiosos que defienden posiciones tradicionales. El mismo recurso de apropiación desviada o incluso invertida de términos utilizados por sus adversarios puede observarse cuando hablan de "acoso estatal" y "abuso estatal", dos nociones ("acoso" y "abuso") centrales de la discursividad feminista.

Por lo demás, la mentada "intromisión del Estado en los asuntos familiares" se refuerza al presentársela como parte de una avanzada proveniente de Europa y de Estados Unidos. De ese modo, se invoca un sentido patriótico en defensa de "nuestras tradiciones", como puede apreciarse en el fragmento de un discurso brindado por Néstor Mercado, vocero de la organización: "Los argentinos a lo largo de la historia hemos peleado batallas terribles. Contra los ingleses, contra los españoles... pero esta vez es por los niños" (Mercado cit. en Con Mis Hijos No Te Metas Rca. Argentina-Oficial-, 14 de diciembre de 2018).

Como ocurriera cuando se discutió la ley que habilitó el matrimonio entre personas del mismo sexo en 2010 y el proyecto que pretendía legalizar la interrupción voluntaria del embarazo en 2018, en este caso también se apeló a la estrategia de "federalizar" el debate, invocando al comúnmente denominado "interior del país" como reservorio inalterado de los auténticos valores morales

Revista Cultura \& Religión Vol. XV, 2021 Nº 1 (enero-junio) 
de la patria, en oposición al cosmopolitismo de la capital (Buenos Aires) que, de acuerdo a esta visión, resultaría más permeable a las costumbres, las modas y los mandatos provenientes del exterior. De ahí que se hayan organizado movilizaciones convocadas bajo el lema \#ConMisHijosNoTeMetas en distintas ciudades, a las que luego se les dio amplia difusión en estas páginas presentándolas como expresión genuina de la "verdadera Argentina".

\section{Pánico sexual y derecho de las mayorías}

La educación sexual integral, que no es ni más ni menos que adoctrinamiento ideológico de género impartido desde las instituciones del Estado. Dentro de este adoctrinamiento centralizado, planificado, sistemático y generalizado también está la pedofilia dentro de la agenda. (Nicolás Márquez cit. en Con mis hijos no te metas Argentina Oficial, 21 de noviembre de 2018 , s. p.)

Desde esta perspectiva se advierte una permanente interpelación a la ciudadanía para que asuma una acción comprometida en el debate. Se trata de activar a una supuesta "mayoría silenciosa" cuya apatía es aprovechada por "minorías poderosas". Un fragmento de una conferencia brindada por Laje expresa esta idea:

El Estado está siendo sometido a dos grandes fuerzas. Por un lado, presiones internacionales están intentando implementar en Argentina ideología de género e introducir el aborto. Pero por otro lado, dado que vivimos en una democracia representativa, existe una fuerza que va de abajo hacia arriba, que es la que va del pueblo hacia sus representantes. En otras palabras, nuestros políticos están condicionados, por un lado, por intereses de organizaciones internacionales, pero por el otro, están también condicionados por nuestro voto, porque lo necesitan para seguir gobernando. Poco y nada podemos hacer nosotros para alterar la magnitud de la fuerza que viene de arriba a abajo. Pero sí podemos incrementar la fuerza que va de abajo a arriba. Somos la mayoría. Pero si enmudecemos,

Revista Cultura \& Religión Vol. XV, 2021 Nº 1 (enero-junio) 95

Romero, G. (2021). Orden, familia y educación sexual. Análisis de la trama de sentidos en torno al movimiento \#conmishijosnotemetas en Argentina. Revista Cultura \& Religión, 15 (1), 75-107 
son las minorías las que se terminan presentando a los políticos como mayoritarias, porque es bien sabido que hace más ruido una persona gritando que mil callando. (cit. en Con mis hijos no te metas Argentina Oficial, 28 septiembre de 2018, s. p.).

De este modo, el movimiento invoca un concepto de democracia que estaría dado por un supuesto "derecho de las mayorías" que, en tanto se mantienen apáticas, terminan siendo avasalladas por minorías poderosas movilizadas por intereses espurios. En esta clave, en las publicaciones de estas páginas se muestran imágenes de docentes trans o con los pañuelos verdes favorables a la legalización del aborto, o estudiantes varones de nivel inicial "vestidos de nenas", así como el izamiento de la bandera del movimiento LGBT en una escuela, empleadas como evidencias innegables de la imposición de estas visiones minoritarias hacia el conjunto de "los chicos". Como señala un flyer publicado en una de las páginas relevadas: "la aceptación de las minorías no puede significar el abandono forzado de toda lógica y sentido común por parte de la mayoría" (Con Mis Hijos No Te Metas República Argentina Buenos Aires "oficial", 29 de octubre de 2018).

La línea argumental trazada inscribe a quienes se identifican con el movimiento \#ConMisHijosNoTeMetas en forma inequívoca dentro de los valores morales mayoritarios y a la propia organización en una suerte de "cruzada" en pos del bien común. Así, las expresiones minoritarias son presentadas como dignas de "respeto", pero atendiendo a evitar su normalización. Su derecho a existir debe ejercerse en el ámbito de lo privado. De otro modo, la inclusión de las minorías deviene en una opresión hacia las mayorías. En esta clave, el vocero Néstor Mercado señala: "yo lo que no estoy de acuerdo es que para otorgarle derecho a una minoría, se le cambie el modelo a una mayoría" (Mercado cit. en Con mis hijos no te metas Argentina Oficial, 1 noviembre de 2018a).

A su vez, esta trama discursiva que asocia la noción de moral pública a la idea de mayoría y esta al concepto de normalidad, tiene su reverso: lo

Revista Cultura \& Religión Vol. XV, 2021 Nº 1 (enero-junio) 96 
minoritario se presenta como anormal y de allí se realiza un desplazamiento de sentido a lo perverso. De este modo, resulta frecuente que las críticas a "las feministas" deriven en referencias a "los pedófilos". Como señala Márquez, coautor junto con Laje de El libro negro de la nueva izquierda (2016):

La ideología de género no se ata a ningún patrón moral, biológico ni natural. Si la sexualidad es una mera construcción, nada nos limita ni nos impide a tener lo que ellos, los lobbys pedófilos, llaman una sexualidad intergeneracional. Qué nos impide que un hombre de 50 años tenga acceso carnal con un niño de 5. [...] Si no tenemos ningún patrón podemos llegar a cualquier extremo. (Márquez cit. en Con mis hijos no te metas Argentina Oficial, 1 de noviembre de 2018, s. p.).

Así, la niñez es representada como un eslabón amenazado y como un espacio moralmente afectado. Como señala Laje en un video en el que establece la asociación entre el aborto y la educación sexual integral:

No les salió el aborto, entonces dijeron vamos a ir con la educación sexual, que la llamaron ESI. La ESI está siendo impulsada por los mismos que impulsaron la campaña pro aborto. ¿Para qué? Para que el día de mañana todos los chicos festejen los abortos. [...] Los mismos que pidieron que los argentinos abortáramos a nuestros hijos, ahora son los que nos dicen cómo tenemos que educar sexualmente a nuestros hijos. (Laje cit. en Con mis hijos no te metas Argentina Oficial, 1 de noviembre de 2018c, s. p.).

Asumiendo que la negativa a la legalización del aborto posee un gran potencial interpelador, se presenta a la ESI como un nuevo eslabón dentro de la misma "agenda de género", pasando por alto que la ley 26.150 está vigente en el país desde el año 2006. Estrategia discursiva acorde con el enfoque del "pánico sexual", concepto que constituye una apropiación en la teoría de género de la noción de "pánico moral" acuñada por diversos estudios sociológicos británicos a principios de la década de 1970 (Elizalde, 2005). Noción que refiere a una ideología difusa que se expresa vagamente en defensa del "bien

Revista Cultura \& Religión Vol. XV, 2021 № 1 (enero-junio) 
común", adaptándose de manera estratégica a diversas situaciones y prácticas emergentes que son definidas como una "amenaza" para el orden público, por lo que merecerían ser controladas, reprimidas y/o sancionadas.

Más que la precisión del objeto al que se alude, el aspecto crucial de este prisma radica en la vinculación con tal objeto a partir de haberlo asumido previamente como un "problema". Incluso podría decirse que la vaguedad característica de estos enunciados refuerza el sentido de amenaza latente y de caos. En esta clave podrían comprenderse las múltiples referencias en las páginas analizadas a las transformaciones producidas en el plano de las identidades de género autopercibidas. Referencias que enhebran relatos de personas que habrían cambiado su identidad de género y se hallan arrepentidas y/o con trastornos psicológicos derivados, presuntos pederastas (siempre varones) que habrían apelado a su edad autopercibida para justificar abusos sexuales de niños/as y hasta "noticias de color", aparentemente grotescas o risibles, pero que contribuyen a delinear un escenario de desorden generalizado que habría que frenar a tiempo. Como se señala en un video ${ }^{11}$ publicado en una de las páginas estudiadas:

Esto de la ideología de género se ha deformado tanto que hoy en día en Europa hay cientos de géneros. [...] En Alemania se ha armado el género animal. Con variables. Por ejemplo, género felino. Y pretenden que su heredero sea su gato. (Con mis hijos no te metas Argentina Oficial, 1 de noviembre de 2018, s. p.).

\section{Conclusiones}

El propósito del artículo consistió en analizar los principales sentidos sociales movilizados por la organización \#ConMisHijosNoTeMetas en Argentina a partir del estudio sistemático de sus tres páginas oficiales de Facebook entre los meses de septiembre de 2018 y marzo de 2019.

${ }^{11}$ Video disponible en

https://www.facebook.com/ConMisHijosNoTeMetasArgentinaOK/posts/516480472167507

Revista Cultura \& Religión Vol. XV, 2021 № 1 (enero-junio) 98

Romero, G. (2021). Orden, familia y educación sexual. Análisis de la trama de sentidos en torno al movimiento \#conmishijosnotemetas en Argentina. Revista Cultura \& Religión, 15 (1), 75-107 
El trabajo da cuenta de que si bien fue el intento de reformar la ESI en septiembre de 2018 lo que apuntaló la actividad del grupo, su foco de atención trasciende con creces la discusión en torno a los artículos de la ley 26.150 que pretenden modificarse, siendo el principal objeto de interés lo que el movimiento denomina "ideología de género", concepto acuñado por el Vaticano a mediados de la década de 1990 y rápidamente adoptado y difundido también por grupos evangélicos.

Como se desprende del análisis esbozado, y en consonancia con los hallazgos de terceros en relación al activismo "provida" (Faur y Viveros, 2020; Gudiño, 2014; Morán, 2012, 2015, 2018; Santamarina, 2020; Tabbush y Caminotti, 2020), la "ideología de género" aparece presentada como parte de una estrategia internacional que pretende imponerse en los distintos países de manera más o menos solapada en el seno de las políticas públicas tendientes a garantizar los “derechos de las minorías". De ese modo, se estaría concretando progresivamente un ataque a los "derechos de las mayorías", convirtiéndose en modelos a seguir expresiones culturales que se presentan como amenazas a los valores tradicionales. En este marco, el lugar estratégico asignado a la educación sexual estaría dado por su capacidad de "aprovecharse" del eslabón más vulnerable de las familias: los/as niños/as. Por lo demás, el riesgo que ello conllevaría surge vinculado a los intereses innobles que los movilizan, como los que representaría el llamado "lobby pedófilo", así como el activismo que impulsa la interrupción voluntaria del embarazo. Aun cuando en ocasiones esa “amenaza" no termina de perfilarse con nitidez, la trama de sentidos construida permite identificar a aquello que ataca el bien común como un enemigo que se presume como no-nacional, no-tradicional y no-normal.

La denuncia de una amenaza externa encarnada en el feminismo y el movimiento LGBT posibilita la expresión de sentimientos de "ofensa moral" que se encuentran en la base de los activismos conservadores y autoritarios contemporáneos (Viotti, 2020). De acuerdo con Viotti, “quien se ve ofendido, se siente vulnerado y reacciona pidiendo orden” (2020, p. 109). Así, el

Revista Cultura \& Religión Vol. XV, 2021 Nº 1 (enero-junio) 
activismo antigénero y sus modalidades de expresión virulenta pueden ser pensadas como "ritualizaciones de un modo muy contemporáneo de sentirse ofendido" (Viotti, 2020, p. 109). De este modo, los discursos neoconservadores darían cuenta no solo de enfoques ideológicos sistemáticos, vinculados a grupos e instituciones sociales (como el aquí estudiado), sino además de la existencia de una nueva "sensibilidad cotidiana" (Viotti, 2020) caracterizada por el sentimiento de una ofensa moral frente a transformaciones socioculturales visualizadas como causantes de desorden, incertidumbre y temor. Siguiendo esta clave interpretativa, futuras indagaciones podrían avanzar sobre las correlaciones entre los trazos discursivos analizados en estas páginas y la experiencia vital de personas que, sin ser parte activa de los grupos provida, se sienten de todos modos interpeladas por su despliegue temático y argumental. La exploración de dichos lazos, con énfasis en sus mediaciones situadas, podría permitirnos complementar el estudio de la trama discursiva movilizada por un movimiento como \#ConMisHijosNoTeMetas (objetivo de este artículo) con la comprensión de sus apropiaciones por parte de distintos sujetos en la reproducción de su vida cotidiana.

En suma, los embates que tanto la ESI como todo un vasto conjunto de políticas con perspectiva de género y derechos humanos vienen experimentando en la actualidad dan cuenta de la importancia de nuevos trabajos que ayuden a comprender los sentidos sociales en pugna. Es el propósito de estas líneas contribuir a ello.

\section{Referencias bibliográficas}

Abela, J. A. (2014). Las técnicas de análisis de contenido: una revisión actualizada. Sevilla: Centro de Estudios Andaluces. Recuperado de http://public.centrodeestudiosandaluces.es/pdfs/S200103.pdf.

Biroli, F. (2020). The Backlash against Gender Equality in Latin America: Temporality, Religious Patterns, and the Erosion of Democracy. 
Dossier: Las ofensivas antigénero en América Latina. LASAForum, 51(2), 22-26. Recuperado de https://sxpolitics.org/es/dossier-lasofensivas-antigenero-en-america-latina-lasa-forum/5004.

Bracamonte, L. (2015). Mujeres y beneficencia: representaciones de género en la prensa católica de Bahía Blanca a principios del siglo XX. Revista Cultura \& Religión, 9(2), 83-99.

Campos Machado, M. (2013). Discursos pentecostais em torno do aborto e da homossexualidade na sociedade brasileira Pentecostal discourses around abortion and homosexuality in Brazilian society. Revista Cultura \& Religión, 7(2), 48-68.

Cáneva, H. (2019). Disputas por el aborto en Argentina: Análisis crítico de discursos en dos organizaciones (2014-2016). (Tesis para optar al título de doctor en Ciencias Sociales), Universidad Nacional de La Plata, Argentina.

Elizalde, S. (2005). La otra mitad. Retóricas de la "peligrosidad" juvenil. Un análisis desde el género. (Tesis para optar al título de doctora en Filosofía y Letras), Universidad de

Esquivel, J. C. (2013). Cuestión de educación (sexual). Pujas y negociaciones político-religiosas en la Argentina democrática. Buenos Aires: Clacso.

Fabris, M. (2015). El movimiento eclesial Comunión y Liberación en la Argentina de la década de 1980. Su lucha contra la secularización y su apuesta por un catolicismo militante. Revista Cultura \& Religión, 9(2), 100-119.

Faur, E. (2020). Educación sexual integral e 'ideología de género' en la Argentina. Dossier: las ofensivas antigénero en América Latina. LASAForum, 51(2), 57-61. Recuperado de https://sxpolitics.org/es/dossier-las-ofensivas-antigenero-en-americalatina-lasa-forum/5004.

Faur, E. y Viveros Vigoya, M. (2020). La ofensiva conservadora contra la "ideología de género" y sus estrategias de avanzada en América Latina". 
Dossier: las ofensivas antigénero en américa latina. LASAForum, 51(2), 11-16. Recuperado de https://sxpolitics.org/es/dossier-las-ofensivasantigenero-en-america-latina-lasa-forum/5004.

Felitti, K. (2011). Estrategias de comunicación del activismo católico conservador frente al aborto y el matrimonio igualitario en la Argentina. Sociedad y Religión, 21(34-35), 92-122.

González Vélez, A. C., Castro, L., Burneo Salazar, C., Motta, A. y Amat y León, O. (2018). Develando la retórica del miedo de los fundamentalismos. La campaña "con mis hijos no te metas" en Colombia, Ecuador y Perú. Lima: Flora Tristán.

Grossberg, L. (2009). El corazón de los estudios culturales: contextualidad, construccionismo y complejidad. Tabula Rasa, 10(2), 13-48.

Gudiño Bessone, P. (2014). Iglesia Católica y activismo provida. Discursos científico-religiosos e intervenciones público-colectivas en torno al aborto. Zona Franca. Revista de Estudios de Género, 22(23), 93-104.

Jones, D. y Carbonelli, M. (2015). La participación política de actores religiosos: los evangélicos frente a los derechos sexuales y reproductivos (2003-2010). En J. C. Esquivel, y J. M. Vaggione (coords.), Permeabilidades activas: religión, política y sexualidad en la Argentina democrática (pp. 75-95). Buenos Aires: Biblos.

Jones, D. y Vaggione, J. M. (2012). Los vínculos entre religión y política a la luz del debate sobre matrimonio para parejas del mismo sexo en Argentina. Civitas, 12(3), 552-537.

Meneses, D. (2019). Con Mis Hijos No te Metas: un estudio de discurso y poder en un grupo de Facebook peruano opuesto a la 'ideología de género'. ANTHROPOLOGICA, 37(42), 129-154.

Morán Faúndes, J. M. (2012). El activismo católico conservador y los discursos científicos sobre sexualidad: cartografía de una ciencia heterosexual. Sociedad y Religión, 22(37), 167-205. 
Morán Faúndes, J. M. (2015). El desarrollo del activismo autodenominado 'Pro-Vida' en Argentina, 1980-2014. Revista Mexicana de Sociología, 77(3), 407-443.

Morán Faúndes, J. M. (2018). Religión, secularidad y activismo héteropatriarcal: ¿qué sabemos del activismo opositor a los derechos sexuales y reproductivos en Latinoamérica? La Ventana. Revista de Estudios de Género, 5(47), 97-138.

Romero, G. (2017). “Chicos, ahora vamos a hablar de sexualidad”. Prácticas, discursos, regulaciones y tensiones en la implementación de la educación sexual en escuelas confesionales católicas de la ciudad de La Plata. (Tesis para optar al título de magíster en Sociología de la Cultura), Universidad de San Martín, Argentina.

Romero, G. (2018). Quiero verte bailar. Género y sexualidad en escuelas secundarias de la ciudad de La Plata. (Tesis para optar al título de doctor en Ciencias Sociales), Universidad de Buenos Aires, Argentina.

Santamarina, S. (2020). "Ideología de género" y activismo político del movimiento provida. El caso de Con Mis Hijos no te Metas en Argentina (2017-2020). (Tesis para optar al título de magíster en Derechos Humanos y Democratización en América Latina y el Caribe), Universidad de San Martín, Argentina.

Sgró, C. (2019). Política sexual y actores religiosos: la oposición católica en la escena mediática argentina. Revista Cultura \& Religión, 13(2), 52-74.

Tabbush, C. y Caminotti, M. (2020). Más allá del sexo: La ampliación de la oposición conservadora a las políticas de igualdad de género en América Latina. Dossier: las ofensivas antigénero en américa latina. LASAForum, 51(2), 27-31. Recuperado de https://sxpolitics.org/es/dossier-las-ofensivas-antigenero-en-americalatina-lasa-forum/5004.

Torres, G. (2014). Iglesia católica, educación y laicidad en la historia Argentina. História da Educacao, 18(44), 165-185.

Revista Cultura \& Religión Vol. XV, 2021 N 1 (enero-junio) 
Vaggione, J. M. (2009). La sexualidad en un mundo post secular. El activismo religioso y los derechos sexuales y reproductivos. En M. Gerlero, Derecho a la sexualidad (pp. 141-159). Buenos Aires: Grimberg.

Viotti, N. (2020). "El individualismo autoritario". 7 ensayos. Revista latinoamericana de sociología, política y cultura. 1. pp.101-114.

\section{Fuentes primarias}

CEA (2007). Educación para el amor. Plan general y cartillas. Buenos Aires: Conferencia Episcopal Argentina.

CEA (2008). Ante la aprobación de los lineamientos curriculares para la educación sexual integral. Documento de la Comisión Episcopal de Educación Católica de la Conferencia Episcopal Argentina. Disponible en https://es.catholic.net/op/articulos/10108/cat/358/ante-la-aprobacionde-los-lineamientos-curriculares-para-la-educacion-sexual-integral.html

Con mis hijos no te metas Argentina Oficial [Agustín Laje] (28 septiembre de 2018). El Estado está siendo sometido a dos grandes fuerzas... [Conferencia de A. Laje]. Facebook. [Recuperado el 6 de agosto de 2019].

https://www.facebook.com/ConMisHijosNoTeMetasArgentinaOK

Con mis hijos no te metas Argentina Oficial [Néstor Mercado] (1 noviembre de 2018a). Yo lo que no estoy de acuerdo es que... [Publicación en Facebook]. Facebook. [Recuperado el 19 de agosto de 2019]. https://www.facebook.com/ConMisHijosNoTeMetasArgentinaOK

Con mis hijos no te metas Argentina Oficial [Nicolás Márquez] (1 de noviembre de 2018b). La ideología de género no se ata a ningún patrón moral... [Publicación en Facebook]. Facebook. [Recuperado el 14 de $\begin{array}{lll}\text { agosto de 2019]. } & \text { de }\end{array}$ https://www.facebook.com/ConMisHijosNoTeMetasArgentinaOK

Revista Cultura \& Religión Vol. XV, 2021 Nº 1 (enero-junio) 104 
Con mis hijos no te metas Argentina Oficial [Agustín Laje] (1 de noviembre de 2018c). No les salió el aborto, entonces dijeron... [Video en Facebook]. Facebook. [Recuperado el 19 de agosto de 2019]. https://www.facebook.com/ConMisHijosNoTeMetasArgentinaOK

Con mis hijos no te metas Argentina Oficial (6 de noviembre de 2018). Esto de la ideología de género se ha deformado tanto... [Video en Facebook]. Facebook. [Recuperado el 16 de agosto de 2019]. https://www.facebook.com/ConMisHijosNoTeMetasArgentinaOK

Con Mis Hijos No Te Metas Argentina Oficial [Nancy García] (8 de noviembre de 2018a). Si bien no son nuestra propiedad... [Declaración verbal]. Facebook. [Recuperado el 26 de agosto de 2019]. https://www.facebook.com/ConMisHijosNoTeMetasArgentinaOK

Con Mis Hijos No Te Metas Argentina Oficial (8 de noviembre de 2018b). La biología, la ciencia y la gente dicen: \#ConMisHijosNoTeMetas. [Spot]. Facebook. [Recuperado el 26 de agosto de 2019]. https://www.facebook.com/ConMisHijosNoTeMetasArgentinaOK

Con mis hijos no te metas Argentina Oficial [Alberto Savazzini] (8 noviembre de 2018c). Hace tiempo un grupo de personas perversas desarrollaron... [Discurso de A. Savazzini]. Facebook. [Recuperado el 26 de agosto].

Con mis hijos no te metas Argentina Oficial [Nicolás Márquez] (21 de noviembre de 2018). La educación sexual integral, que no es ni más ni menos... [Publicación en Facebook]. Facebook. [Recuperado el 1 de septiembre de 2019]. https://www.facebook.com/ConMisHijosNoTeMetasArgentinaOK

Con mis hijos no te metas Argentina Oficial [Agustín Laje] (26 noviembre de 2018). Es imperioso entender que el aborto... [Declaración verbal]. Facebook. [Recuperado el 3 de septiembre de 2019]. https://www.facebook.com/ConMisHijosNoTeMetasArgentinaOK 
Con mis hijos no te metas Argentina Oficial [Agustín Laje]. (28 noviembre de 2018). Están utilizando al Estado para hacer obligatoria su ideología. ... [Declaración verbal]. Facebook. [Recuperado el 3 de septiembre de 2019].

https://www.facebook.com/ConMisHijosNoTeMetasArgentinaOK

Con mis hijos no te metas Argentina Oficial [Agustín Laje] (12 enero de 2019). Nosotros no vamos a tener la plata de George Soros... [Video en Facebook]. Facebook. [Recuperado el 6 de septiembre de 2019]. https://www.facebook.com/ConMisHijosNoTeMetasArgentinaOK

Con Mis Hijos No Te Metas Rca. Argentina-Oficial- [Néstor Mercado] (13 noviembre de 2018). Se quiere quitar la posibilidad de... [Declaración verbal]. Facebook. [Recuperado el 26 de agosto de 2019]. https://www.facebook.com/search/top?q=Con\%20Mis\%20Hijos\%20No $\% 20 \mathrm{Te} \% 20 \mathrm{Metas} \% 20 \mathrm{Rca} \% 20$ Argentina-Oficial-

Con Mis Hijos No Te Metas Rca. Argentina-Oficial- [Néstor Mercado] (14 de diciembre de 2018). Los argentinos a lo largo de la historia... [Discurso de N. Mercado]. Facebook. [Recuperado el 26 de agosto de 2019]. https://www.facebook.com/search/top?q=Con\%20Mis\%20Hijos $\% 20 \mathrm{No}$ \%20Te\%20Metas\%20Rca.\%20Argentina-Oficial-

Con Mis Hijos No Te Metas República Argentina Buenos Aires "oficial" (29 de octubre de 2018). La aceptación de las minorías no puede significar... [Flyer de Facebook]. Facebook. [Recuperado el 19 de agosto de 2019]. https://www.facebook.com/Conmishijosnotemetasrepublicaargentinabue nosaires

Con Mis Hijos No Te Metas República Argentina Buenos Aires "oficial" (11 de diciembre de 2018). Cómo se nota que tienen mucha guita [dinero]... [Publicación en Facebook]. Facebook. [Recuperado el 26 de agosto de 2019]. https://www.facebook.com/Conmishijosnotemetasrepublicaa rgentinabuenosaires

Revista Cultura \& Religión Vol. XV, 2021 Nº 1 (enero-junio 
InfoCatólica (2016). Puesta de largo de la campaña \#ConMisHijosNoTeMetas en Perú. Recuperado de https://www.infocatolica.com/?t=opinion\& $\operatorname{cod}=27909$

Ley Educación Sexual Integral de la República Argentina. 23 de octubre de 2006, $\mathrm{N}^{\circ} 26.150$.

Ley de Educación Nacional de la República Argentina. 27 de diciembre de 2006, $\mathrm{N}^{\circ} 26.206$.

Ley de Protección Integral de los Derechos de la Niñez y la Adolescencia de la República Argentina. 21 de octubre de 2005, № 26.061.

Márquez, N. y Laje, A. (2016). El libro negro de la nueva izquierda. Ideología de género o subversión cultural. Buenos Aires: Libre-Grupo Unión.

Sistema de Información Cultural de la Argentina (2017). Los jóvenes y los consumos culturales. [En línea]. Recuperado de https://www.sinca. gob.ar/VerDocumento.aspx?IdCategoria $=10$

\footnotetext{
* Este trabajo se inscribe en una investigación de mayor alcance realizada en el marco de una beca posdoctoral, otorgada por el Consejo Nacional de Investigaciones Científicas y Técnicas de Argentina (Conicet), titulada "Tecnologías, redes sociales y activismos de género en la escuela secundaria. Apropiaciones, desafíos y resistencias".

*** Licenciado y profesor en Comunicación Social, Universidad Nacional de La Plata (UNLP). Magíster en Sociología de la Cultura, Universidad Nacional de San Martín (UNSAM) y doctor en Ciencias Sociales, Universidad de Buenos Aires (UBA). Becario posdoctoral del Consejo Nacional de Investigaciones Científicas y Técnicas (CONICET), con sede en el Instituto Interdisciplinario de Estudios de Género (IIEGE) de la Facultad de Filosofía y Letras (UBA). guiromero10@hotmail.com
} 